Article

\title{
Design of Ethylene-Vinyl Acetate Copolymer Fiber with Two-Way Shape Memory Effect
}

\author{
Xiaoming Qi, Wentong Yang, Laiming Yu, Wenjun Wang, Haohao Lu, Yanglong Wu, \\ Shanwen Zhu, Yaofeng Zhu, Xiangdong Liu, Yubing Dong * $\mathbb{D}$ and Yaqin Fu *
}

Key Laboratory of Advanced Textile Materials and Manufacturing Technology Ministry of Education, Zhejiang Sci-Tech University, Hangzhou 310018, China; xmqi19931127@163.com (X.Q.); 819177316ywt@163.com (W.Y.); kyokylin@126.com (L.Y.); wangwj310@163.com (W.W.); mrluhaohao@163.com (H.L.); mrwy10818@163.com (Y.W.); zswae86@163.com (S.Z.); yfzhu@zstu.edu.cn (Y.Z.); liuxd@zstu.edu.cn (X.L.)

* Correspondence: dyb19831120@zstu.edu.cn (Y.D.); fyq01@zstu.edu.cn (Y.F.)

Received: 23 August 2019; Accepted: 27 September 2019; Published: 30 September 2019

check for updates

\begin{abstract}
One-dimensional shape memory polymer fibers (SMPFs) have obvious advantages in mechanical properties, dispersion properties, and weavability. In this work, a method for fabricating semi-crystallization ethylene-vinyl acetate copolymer (EVA) fiber with two-way shape memory effect by melt spinning and ultraviolet (UV) curing was developed. Here, the effect of crosslink density on its performance was systematically analyzed by gel fraction measurement, tensile tests, DSC, and TMA analysis. The results showed that the crosslink density and shape memory properties of EVA fiber could be facilely adjusted by controlling UV curing time. The resulting EVA fiber with cylindrical structure had a diameter of $261.86 \pm 13.07 \mu \mathrm{m}$, and its mechanical strength and elongation at break were $64.46 \mathrm{MPa}$ and $114.33 \%$, respectively. The critical impact of the crosslink density and applied constant stress on the two-way shape memory effect were analyzed. Moreover, the single EVA fiber could lift more than 143 times its own weight and achieve $9 \%$ reversible actuation strain. The reversible actuation capability was significantly enhanced by a simple winding design of the single EVA fiber, which provided great potential applications in smart textiles, flexible actuators, and artificial muscles.
\end{abstract}

Keywords: shape memory polymer fiber; two-way shape memory effect; melt spinning; UV curing

\section{Introduction}

Smart materials as an emerging key technology, will provide unique capabilities for new products. The special feature of smart materials is active "smart" response rather than sensing, such as self-sensing, self-healing, self-actuating, self-diagnostic, and shape changing [1]. As an important branch of smart materials, shape memory polymers (SMPs) can memorize temporary shape and return to their initial shape when exposed to external stimuli (such as heat, light, electricity, magnetic field, solvent, and $\mathrm{pH}$ [2-11]. Furthermore, SMPs have extraordinary advantages due to its light weight, low cost, flexibility, large deformation, and easy manufacture process compared to shape memory alloys and shape memory ceramics. These unique properties have potential in diverse applications, ranging from aerospace [5], sensors [12,13], and actuators [14,15] to smart textiles [16,17], self-healing [18,19], and artificial muscles $[20,21]$.

Over the past few decades, a variety of structural SMPs have emerged, including shape memory films [22], shape memory foams [23-25], and shape memory polymer fibers (SMPFs) [16,26,27]. Although shape memory films and foams have their own superiority and applications, the one-dimensional orientation of SMPFs with excellent mechanical properties, greater recovery stress, and faster response 
speed greatly enhances the functionality of SMPs [28]. Li et al. proposed that SMPFs have good mechanical properties and dispersibility, and it provided excellent self-healing ability for the intelligent composites $[29,30]$. When the composites were damaged, the driving force for self-healing was supplied by the SMPFs. The cold-drawing SMPFs restore the shrinkage stress when the composites were heated above the glass transition temperature of the SMPFs. Moreover, SMPFs can be woven into smart comfort-adjusting textile and actively adjust their porosity in response to changes in the external environment [31,32].

SMPFs are mainly fabricated from thermoplastic SMPs, especially polyurethane (PU). SMPFs based on PU with micro-phase-separated structure, in which the hard segment as the physical crosslink and the soft segment as the transition phase memory temporary shape. The response temperature and mechanical properties of the PU fiber can be adjusted by varying the ratio of hard and soft segments [33]. Recently, two-way SMPs (2W-SMPs) based on semi-crystalline polymers have achieved great progress. 2W-SMPs can exhibit a two-way shape memory effect (2W-SME) without external programming [34-36]. This feature is expected to make 2W-SMPs an ideal candidate for actuators, artificial muscles, and self-locomotion robots. Combined with intelligent material characteristics and fiber processing techniques, the researchers reported variety of smart twisted fiber with reversible actuation $[37,38]$. However, the production of large-scale twisted fiber-based artificial muscles in an efficient manner still presents challenges. Therefore, the efficient preparation of intelligent two-way shape memory fibers based on semi-crystalline polymers is one of the research hotspots.

Considering the molecular structure of 2W-SMPs, the premise of fiber with 2W-SME is that the fibers must have crosslinked network. Commercial semi-crystalline polymers such as polyethylene, polypropylene, poly( $\varepsilon$-caprolactone), and ethylene-vinyl acetate copolymer (EVA) have been widely used to design 2W-SMPs due to their low cost and ease of processing [39-44]. Our previous research indicated that EVA with crystallization and crosslinked structure exhibited melting induced contraction (MIC) and crystallization induced elongation (CIE) under constant stress and stress-free conditions [42,45]. In general, commercial semi-crystalline EVA can be easily processed into fibers. Therefore, the crosslinked network structure is important to manufacturing EVA fiber with $2 \mathrm{~W}-\mathrm{SME}$. At present, most researchers fabricated the crosslinked EVA film by using a thermally induced free radical reaction. Upon heating above the thermally induced free radical temperature, the macroscopic shrinkage and plastic flow of EVA fiber would occur due to melt transition. Therefore, it is critical to crosslink EVA fiber at room temperature to avoid the structure damages. In the last five years, SMPFs with nano- or micro-scale fibrous structures were obtained by electrospinning [46-49], the crosslinked network has been obtained though free radical reaction initiated by ultraviolet (UV). The mild temperature (lower than Tm) of the UV curing avoids losing its fibrous structure while obtaining a crosslinked network. Compared to electrospinning fiber membranes, the single fibers prepared by melt spinning can be assembled in an orderly manner to form a more diverse variety of yarn, braid, and fabric, respectively.

In this study, EVA fiber was first prepared by efficient and convenient melt spinning, benzophenone and triallyl isocyanurate were introduced to EVA fiber as photoinitiator and multi-functional crosslinking agent, respectively. A series of EVA fibers with different crosslink density were prepared by controlling the UV curing time. The effect of the crosslink density on the mechanical, thermal, and shape memory properties of EVA fiber was discussed. In addition, the impact of the crosslink density and the constant stress for 2W-SME were investigated. Moreover, the EVA fiber could lift more than 143 times its own weight and achieve 9\% reversible actuation strain. The EVA fiber may have great potential in smart textiles, flexible actuators, and artificial muscles. 


\section{Materials and Methods}

\subsection{Materials}

EVA with a vinyl acetate content of $18 \mathrm{wt} \%$ and melt index $2.5 \mathrm{~g} / \mathrm{min}$ (Elvax460, DuPont), benzophenone (BP) (99\%) and triallyl isocyanurate (TAIC) (contains 500 ppm BHT stabilizer) were purchased from Aladdin Reagent, Shanghai, China. Xylene (99\%) was purchased from commercial (Hangzhou Gaojing Fine Chemical Co., Ltd., Hangzhou, China). All the chemicals were used as received.

\subsection{Fabrication of EVA Fiber}

EVA, BP, and TAIC were pre-mixed at a mass ratio of 98:1:1, and then, the mixture was melt-extruded using a micro twin-screw extruder (SJSZ-10A, Wuhan Ruiming, Wuhan, China). The temperatures of the extruder heating zone were set to $130{ }^{\circ} \mathrm{C}, 135^{\circ} \mathrm{C}, 145^{\circ} \mathrm{C}$, and $150{ }^{\circ} \mathrm{C}$, the screw main engine speed was 40-50 rpm, the feed rod speed was 30-40 rpm. The EVA fiber was drawn and collected by a speed-regulating rotor, which drafting speed at $15-20 \mathrm{~m} / \mathrm{min}$. The extrusion speed was 1-2 $\mathrm{m} / \mathrm{min}$ and extrusion die to collection roller distance was $100 \mathrm{~cm}$. The EVA fibers were separated from the collection roller and cured using a UV lamp with the main wavelength of $365 \mathrm{~nm}\left(800 \mu \mathrm{w} / \mathrm{cm}^{2}\right)$, and schematic of the fabrication process as shown in Figure 1a. The curing time was set to $2 \mathrm{~min}, 4 \mathrm{~min}$, $6 \mathrm{~min}, 8 \mathrm{~min}$, and $10 \mathrm{~min}$, five crosslinked EVA fibers were obtained and named as EVA-2M, EVA-4M, EVA-6M, EVA-8M, and EVA-10M, respectively.
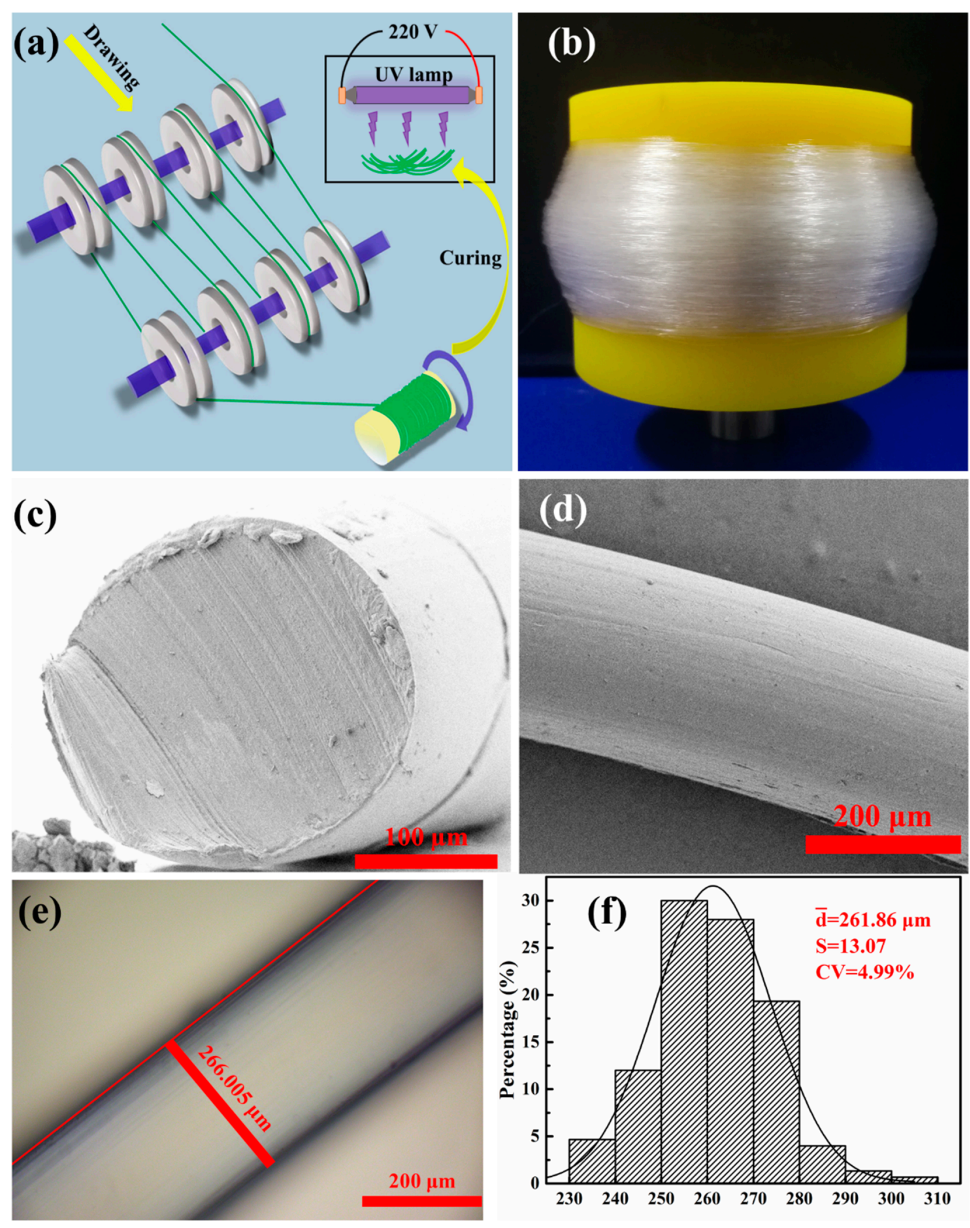

Figure 1. (a) Preparation schematic of drawing and ultraviolet (UV) curing; (b) digital photograph of ethylene-vinyl acetate (EVA) fiber before UV curing; (c,d) the SEM images of EVA fiber after UV curing; $(\mathbf{e}, \mathbf{f})$ the optical micrograph and diameter distribution of EVA fiber after UV curing. 


\subsection{Morphology Characterization}

The EVA fiber was sputter-coated with gold and observed through scanning electron microscopy (FE-SEM) at an accelerated voltage of $3.0 \mathrm{kV}$. The diameter of samples was measured using a polarized light microscope (DM2700P, Leica, Wetzlar, Germany). The measurement of diameter distribution and coefficient of variation (CV) referred to the standard SN/T 2672-2010. The interval of EVA fiber diameter measurement was $5 \mathrm{~mm}$ with a specimen number of 300 . The samples were placed in a chamber with constant temperature and humidity for $24 \mathrm{~h}$ (temperature of $20 \pm 2{ }^{\circ} \mathrm{C}$, relative humidity of $65 \% \pm 4 \%$ ) before testing.

\subsection{Gel Fraction Measurement}

Each crosslinked EVA fiber was wrapped with a $100 \mathrm{M}$ copper mesh and immersed in xylene, and then, it was heated to $140{ }^{\circ} \mathrm{C}$ and kept for $12 \mathrm{~h}$. The sample after extraction was completely dried in a vacuum oven at $60^{\circ} \mathrm{C}$. The gel mass fraction $(G)$ of crosslinked EVA fiber was calculated by Equation (1):

$$
G=\frac{m_{2}-m_{0}}{m_{1}-m_{0}} \times 100 \%
$$

where $m_{0}$ is the mass of the copper mesh, $m_{1}$ and $m_{2}$ are the mass of the total mass of sample and copper mesh before and after extraction, respectively.

\subsection{Thermal and Mechanical Properties Tests}

The crystallization and melting behavior of EVA fiber were characterized by differential scanning calorimetry (DSC Q2000, TA Instruments, New Castle, DE, America) under nitrogen. The fibers were first raised to $130{ }^{\circ} \mathrm{C}$ and insulation for $3 \mathrm{~min}$ to eliminate thermal history. Then, the samples were cooled to $20^{\circ} \mathrm{C}$ and heated to $130^{\circ} \mathrm{C}$ again. The heating change rate was $10^{\circ} \mathrm{C} / \mathrm{min}$. The measurement of fractional crystallinity $\left(X_{\mathrm{c}}\right)$ of samples referred to [50].

The room-temperature tensile tests of EVA fiber were conducted using a multi-purpose tensile tester (KES-G1, Kato Tech Co., Kyoto, Japan). Cylinder-shaped specimens with a length of $15 \mathrm{~mm}$ were stretched at a strain speed of $6 \mathrm{~mm} / \mathrm{min}$.

\subsection{Shape Memory Experiments}

1W- and 2W-SME of EVA fiber were measured by the TMA Q400 (TA Instruments, New Castle, $\mathrm{DE}$, America) in dynamic DMA mode following previous research [11,42]. 1W-SME was investigated by the following four steps. First, the EVA fiber was raised to high temperature ( $T_{\text {high }}$ at $100{ }^{\circ} \mathrm{C}$ ) and creep at $100{ }^{\circ} \mathrm{C}$ for $10 \mathrm{~min}$. Second, the stress was added to obtain tensile strain. After stress was maintained for $5 \mathrm{~min}$, the temperature was cooled to low temperature $\left(T_{\text {low }}\right.$ at $\left.20^{\circ} \mathrm{C}\right)$ and the stress was released. Finally, the temperature was reheated to $T_{\text {high }}$ and the temporary shape of fiber recovered. The difference between $1 \mathrm{~W}$ - and $2 \mathrm{~W}$-SME was that the stress applied in the second step was retained. The temperature and stress change rates were $10^{\circ} \mathrm{C} / \mathrm{min}$ and $0.05 \mathrm{MPa} / \mathrm{min}$, respectively. The shape memory cycles under different stresses were repeated five times. Notably, the additional stress (ca. $0.17 \mathrm{MPa}$ ) was generated by the TMA fixture due to its own weight. Therefore, the sample was tested under the gravity of the TMA fixture. In the thermo-mechanical cycle curve, the thermal shrinkage strain fixation rate $\left(R_{\mathrm{s}}\right)$ was determined by Equation (2):

$$
R_{s}=\frac{S_{s}-S_{c}}{S_{S}} \times 100 \%
$$

where $S_{\mathrm{s}}$ and $S_{\mathrm{c}}$ are the thermal shrinkage strain and creep strain of the fibers under 0.17 MPa. 
The shape fixity ratio $\left(R_{\mathrm{f}, 1 \mathrm{~W}}\right)$ and shape recovery ratio $\left(R_{\mathrm{r}, 1 \mathrm{~W}}\right)$ of $1 \mathrm{~W}-\mathrm{SME}$ and the actuation strain $\left(R_{\mathrm{a}, 2 \mathrm{~W}}\right)$ and two-way shape recovery ratio $\left(R_{\mathrm{r}, 2 \mathrm{~W}}\right)$ of $2 \mathrm{~W}$-SME were calculated by Equations (3)-(6) [42]:

$$
\begin{gathered}
R_{f, 1 W}=\frac{\varepsilon_{\text {unload }}-\varepsilon_{\text {inital }}}{\varepsilon_{\text {load }}-\varepsilon_{\text {inital }}} \times 100 \% \\
R_{r, 1 W}=\frac{\varepsilon_{\text {unload }}-\varepsilon_{\text {rec }}}{\varepsilon_{\text {unload }}-\varepsilon_{\text {inital }}} \times 100 \% \\
R_{a, 2 W}=\left(\varepsilon_{\text {low }}-\varepsilon_{\text {high }}\right) \times 100 \% \\
R_{r, 2 W}=\frac{\varepsilon_{\text {low }}-\varepsilon_{\text {high }}}{\varepsilon_{\text {low }}-\varepsilon_{0}} \times 100 \%
\end{gathered}
$$

In Equations (3) and (4), $\varepsilon_{\text {inital }}$ is the strain of the sample at $T_{\text {high }}$ before applying stress, $\varepsilon_{\text {load }}$ is the maximum strain under load, $\varepsilon_{\text {unload }}$ is the fixed strain after cooling and stress removal, and $\varepsilon_{\text {rec }}$ is the strain after reheating and recovery. In Equations (5) and (6), $\varepsilon_{0}$ represents the strain after programming at $T_{\text {high }}$ and $\varepsilon_{\text {low }}$ correspond to the strain after a complete crystallization-induced elongation at $T_{\text {low }}$, respectively. Moreover, $\varepsilon_{\text {high }}$ represents the strain after complete melting-induced contraction caused by reheating to $T_{\text {high }}$.

\section{Results and Discussion}

\subsection{Morphology of EVA Fiber}

Melted EVA mixed with BP and TAIC was extruded and drawn using laboratory-made drawing equipment. EVA continuous filament was stably prepared by efficient and convenient melt spinning (see Figure 1b), and the average diameter of the EVA fiber was $261.86 \pm 13.07 \mu \mathrm{m}(\mathrm{CV}=4.99 \%)$ as shown in Figure 1e,f. In the second step, EVA fiber with chemical crosslinking network was fabricated by UV curing, and BP and TAIC were photoinitiator and multi-functional crosslinking agent, respectively. The gel fraction $(\mathrm{G})$ of EVA fibers was in the range of $1.62-43.68 \%$ according to the different UV curing time, indicated that the crosslink density of EVA fiber could be conveniently adjusted by changing the UV curing time [51]. When exposed to UV lamp, the initiator benzophenone changes from the ground state to the excited state after absorbing UV energy, and the excited benzophenone can undergo hydrogen abstraction reaction with the EVA and TAIC molecular chains, leading to the generation free radicals. Therefore, the free radicals of the EVA molecular chain can not only crosslink with other EVA molecular chains (reaction 1) but also react with the TAIC molecular groups (reaction 2 and 3), as shown in Figure 2. The addition of TAIC helps to reduce chain scission reactions and increase crosslinking of EVA fiber [52,53]. UV curing at room temperature preserves the complete structure of EVA fiber, and the morphology after crosslinking was shown in Figure 1c,d. The regular cylindrical profile and smooth surface of the fiber were apparent. Owing to the mild conditions of UV curing, no significant change in fiber structure was observed. This method is considered efficient and convenient for the manufacture of crosslinking EVA fiber. 


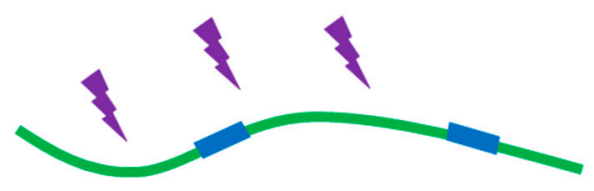

EVA molecular chain

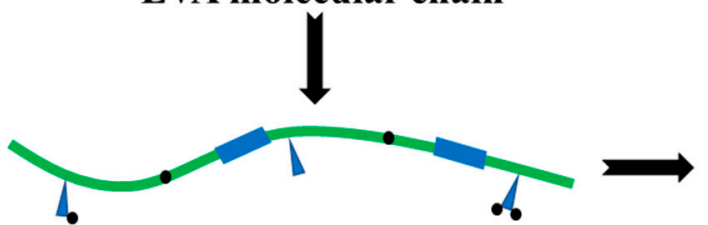

EVA molecular chain radicals

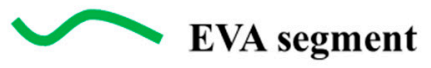

\section{Crystalline PE domains}

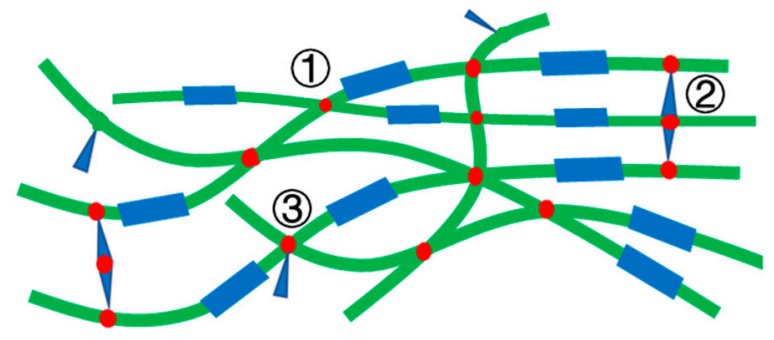

Free-radical couple crosslinking

\section{TAIC}

- $\quad$ Free radical

- Crosslinking point

Figure 2. Schematic illustration of the crosslinking EVA fiber via free radical reaction initiated by UV.

\subsection{Thermal and Mechanical Properties of EVA Fiber}

The values of $T_{\mathrm{m}}$ and $T_{\mathrm{c}}$ were calculated as the peak temperature of the corresponding heat flow curves as shown in Figure 3 and listed in Table 1. $T_{\mathrm{m}}$ slightly decreased from 82.37 to $79.63{ }^{\circ} \mathrm{C}$ (the standard deviation of $T_{\mathrm{m}}$ was 0.953 ) with the curing time increasing. The same decreasing trend was obtained for $T_{\mathrm{C}}$ and $X_{\mathrm{c}}$ (the standard deviation of $T_{\mathrm{c}}$ and $X_{\mathrm{c}}$ was 0.371 and 0.994 , respectively). This observation was caused by the increase in crosslink density, which impedes the movement of the molecular chain and crystal growth. Meanwhile, the self-adjustment ability and chain mobility of the chain segments decreased due to the crosslinked network and then restrict the growth of EVA crystals $[40,44]$. Owing to good orientation in the drafting process, the mechanical properties of EVA fiber have been remarkably enhanced. When the curing time was $4 \mathrm{~min}$, the tensile strength and elongation at break reached a maximum of $69.95 \mathrm{MPa}$ and $159.33 \%$, respectively. The mechanical properties can be improved by suitable crosslinking. On the contrary, the tensile strength lightly decreased from $67.93 \mathrm{MPa}$ to $64.46 \mathrm{MPa}$ when the curing time increased from $6 \mathrm{~min}$ to $10 \mathrm{~min}$. A similar trend was noticed for elongation at break between $143.66 \%$ and $114.33 \%$ (see Table 1 ). This result may be due to UV aging [54]. It is worth noting that the mechanical properties of EVA fiber was improved by nearly $485 \%$ compared to the reported two-way shape memory EVA film, owing to the molecular chain orientation which was realized in melting spinning [42].
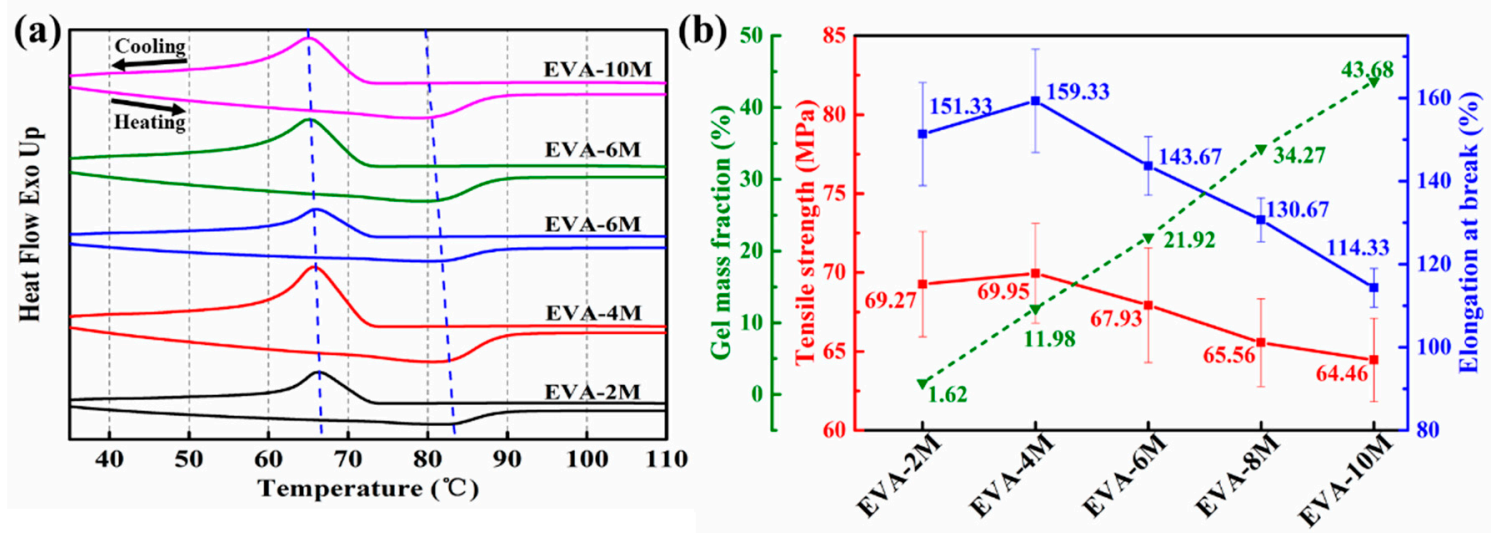

Figure 3. (a) DSC heating and cooling curves and (b) physical properties of different EVA fiber. 
Table 1. Physical and mechanical properties of different EVA fiber.

\begin{tabular}{ccccccc}
\hline Samples & $\begin{array}{c}\boldsymbol{T}_{\mathbf{m}} \\
\left({ }^{\circ} \mathbf{C}\right)\end{array}$ & $\begin{array}{c}\boldsymbol{T}_{\mathbf{c}} \\
\left({ }^{\circ} \mathbf{C}\right)\end{array}$ & $\begin{array}{c}G \\
(\mathbf{\%})\end{array}$ & $\begin{array}{c}\boldsymbol{X}_{\mathbf{c}} \\
(\mathbf{\%})\end{array}$ & $\begin{array}{c}\text { Tensile Strength } \\
\mathbf{( M P a )}\end{array}$ & $\begin{array}{c}\text { Elongation at Break } \\
\mathbf{( \% )}\end{array}$ \\
\hline EVA-2M & 82.37 & 66.25 & 1.62 & 19.42 & $69.27 \pm 3.34$ & $151.33 \pm 12.39$ \\
EVA-4M & 81.87 & 65.82 & 11.98 & 18.73 & $69.95 \pm 3.16$ & $159.33 \pm 12.40$ \\
EVA-6M & 81.25 & 65.75 & 21.92 & 17.60 & $67.93 \pm 3.63$ & $143.66 \pm 7.07$ \\
EVA-8M & 80.69 & 65.16 & 34.27 & 16.86 & $65.56 \pm 2.78$ & $130.67 \pm 5.27$ \\
EVA-10M & 79.63 & 65.42 & 43.68 & 17.02 & $64.46 \pm 2.65$ & $114.33 \pm 4.65$ \\
\hline
\end{tabular}

\subsection{Creep and $2 W-S M E$ of EVA Fiber}

The thermal shrinkage and creep behavior of EVA fiber with different curing time were shown in Figure 4. All samples exhibited approximately $40 \%$ heat shrinkage during the heating process. Notably, the crosslink density of EVA-2M was too low to break, which evidently did not achieve shape memory (Figure 4a). The different creep behaviors were observed in Figure $4 \mathrm{~b}-\mathrm{e}$, the $R_{\mathrm{s}}$ increased from $29.14 \%$ to $76.39 \%$ as the curing time increased. Therefore, the reversible shape memory transition in different strain ranges was exhibited under $0.17 \mathrm{MPa}$. The plastic flow of the molecular chains was limited by increasing the crosslink density of EVA fiber, which increases its cyclic stability. Moreover, the significant elongation occurred during the cooling process (see Figure $4 \mathrm{~b}-\mathrm{e}$ ). The $2 \mathrm{~W}-\mathrm{SME}$ cycles of EVA-4M, -6M, -8M, and -10M under 0.17 MPa in detail as presented in Figure 4f. EVA-4M had a large reversible strain $(>10 \%)$ under $0.17 \mathrm{MPa}$, but its cycle stability was poor due to large creep. In fact, SME strongly depends on the crosslink density and deformation stress [36,40]. Therefore, EVA-6M, EVA-8M, and EVA-10M were chosen as the study components and discussed the effects of different crosslink densities and deformation stresses on 1W-SME and two-way reversible strain comprehensively.
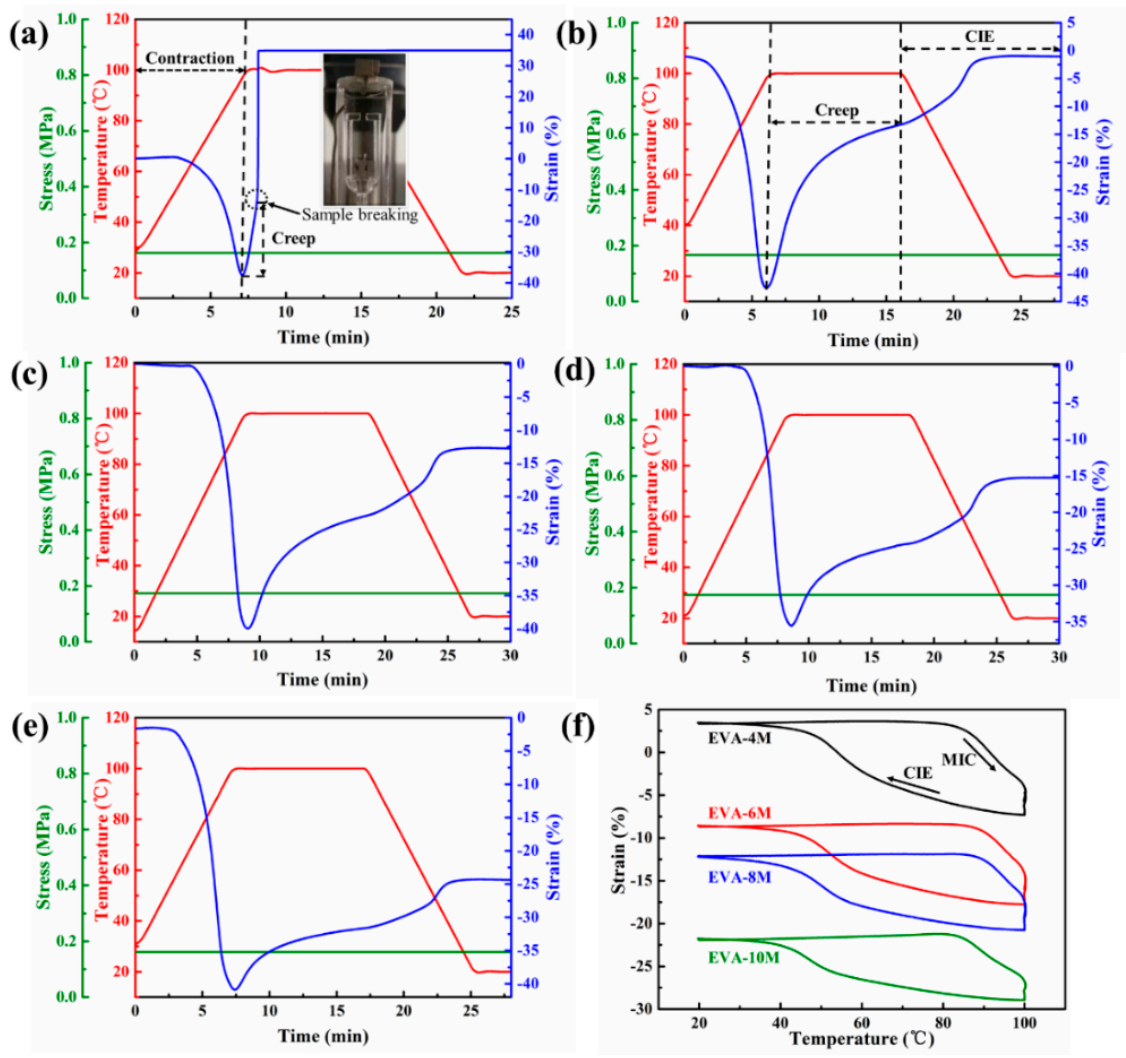

Figure 4. Thermal contraction and creep behavior under a constant stress of $0.17 \mathrm{MPa}$ for (a) EVA-2M, (b) EVA-4M, (c) EVA-6M, (d) EVA-8M, and (e) EVA-10M. (f) Two-way shape memory effect (2W-SME) cycle curves of EVA fiber under a constant stress of $0.17 \mathrm{MPa}$ with different UV curing time. 


\section{4. $1 W$ - and $2 W-S M E$ of EVA Fiber}

EVA fibers with large crosslink density were chosen to test $1 \mathrm{~W}$ - and 2W-SME for avoiding breakage of the samples. The fiber underwent heating-cooling cycles between 20 and $100{ }^{\circ} \mathrm{C}$ five times under $0.27 \mathrm{MPa}$ (Figures 5 and 6 ). The $R_{\mathrm{f}, 1 \mathrm{~W}}$ and $R_{\mathrm{r}, 1 \mathrm{~W}}$ of different EVA fiber for each heating-cooling cycle were calculated from Figure 5. They remain nearly constant (all higher than $95 \%$ ) as the crosslink density increased (Table 2). This result is consistent with previous research by Li et al. [36]. However, it should be noted that shape memory transforms in different strain ranges was observed due to the heat shrinkage and creep. The plastic flow of the molecular chain was limited due to the increased crosslink density of EVA fibers, resulting in the improved thermal mechanical property. Therefore, the shape memory transition in different strain ranges was exhibited when the external stress was increased to $0.27 \mathrm{MPa}$. For example, Figure $5 \mathrm{a}, \mathrm{c}$ show the shape memory process in the stretched and contracted states (relative to the initial length), respectively. Moreover, the significant MIC and CIE emerge during each heating-cooling cycle [55]. The $R_{\mathrm{a}, 2 \mathrm{~W}}$ of EVA-6M was only $8.69 \%$ after five cycles, and there was a downward trend as shown in Figure 5a and Table 3. Most importantly, the $R_{\mathrm{a}, 2 \mathrm{~W}}$ of EVA-8M and EVA-10M was $13.35 \%$ and $12.26 \%$, respectively. It was larger than EVA-6M under the same crystallization condition and stress. Previous research had shown that the constrained effect of the crosslinked network influences the oriented crystallization under different stresses [56,57]. EVA-6M with a relatively low crosslink density does not achieve the expected two-way shape memory effect despite its good one-way shape performance. Overall, Figures 5 and 6 showed that: An appropriate crosslink density was indispensable to ensure larger loads and greater reversible strain.
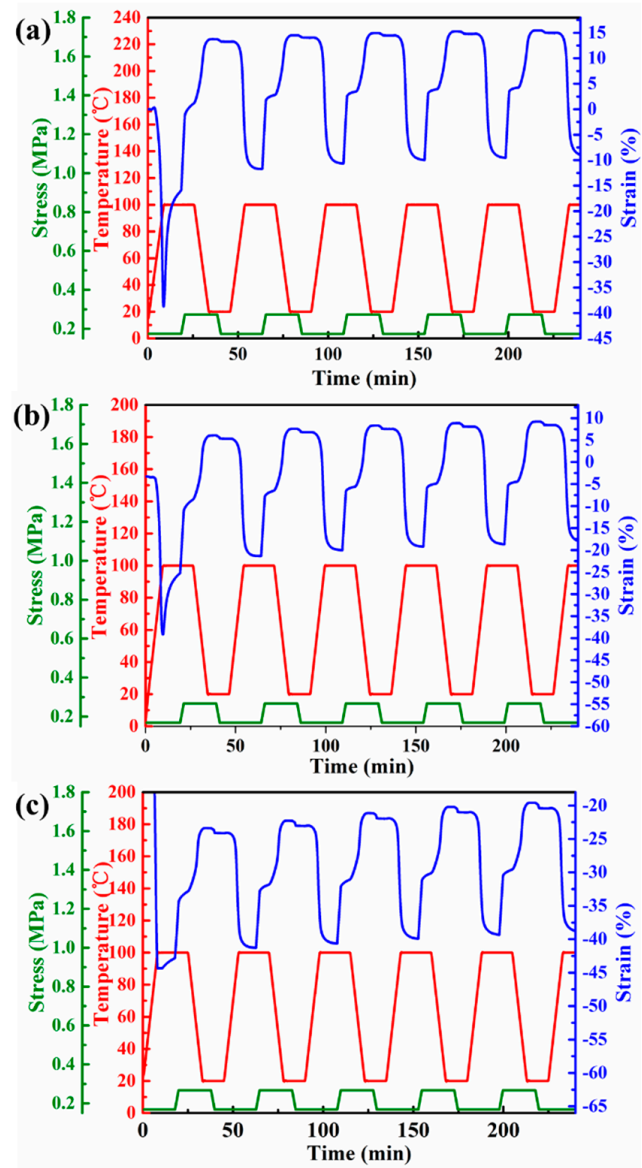

Figure 5. 1W-SME cycles under a constant stress of $0.27 \mathrm{MPa}$ for (a) EVA-6M, (b) EVA-8M, and (c) EVA-10M. 

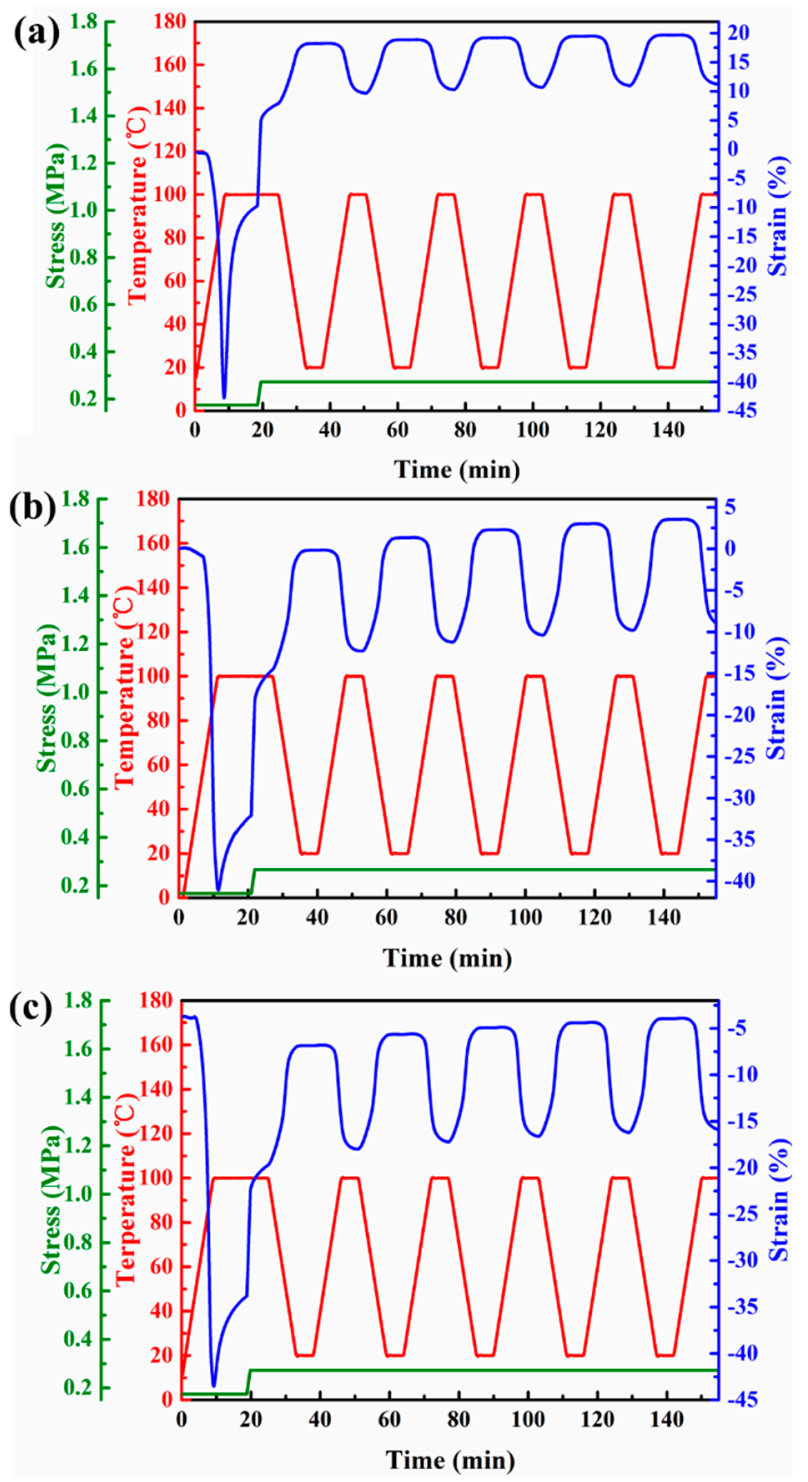

Figure 6. 2W-SME cycles under a constant stress of $0.27 \mathrm{MPa}$ for (a) EVA-6M, (b) EVA-8M, and (c) EVA-10M.

Table 2. One-way (1W)-SME of different EVA fiber under 0.27 MPa.

\begin{tabular}{ccccccc}
\hline \multirow{2}{*}{ Cycles } & \multicolumn{2}{c}{ EVA-6M } & \multicolumn{2}{c}{ EVA-8M } & \multicolumn{2}{c}{ EVA-10M } \\
\cline { 2 - 7 } & $\begin{array}{c}\boldsymbol{R}_{\mathbf{f}, \mathbf{1 W}} \\
\mathbf{( \% )}\end{array}$ & $\begin{array}{c}\boldsymbol{R}_{\mathbf{r}, \mathbf{1 W}} \\
\mathbf{( \% )}\end{array}$ & $\begin{array}{c}\boldsymbol{R}_{\mathbf{f}, \mathbf{1 W}} \\
\mathbf{( \% )}\end{array}$ & $\begin{array}{c}\boldsymbol{R}_{\mathbf{r}, \mathbf{1 W}} \\
\mathbf{( \% )}\end{array}$ & $\begin{array}{c}\boldsymbol{R}_{\mathbf{f}, \mathbf{1 W}} \\
\mathbf{( \% )}\end{array}$ & $\begin{array}{c}\boldsymbol{R}_{\mathbf{r}, \mathbf{1 W}} \\
\mathbf{( \% )}\end{array}$ \\
\hline 1 & 98.39 & 85.32 & 97.58 & 87.88 & 95.86 & 92.28 \\
2 & 98.21 & 95.73 & 97.33 & 95.20 & 95.94 & 96.32 \\
3 & 98.24 & 97.25 & 97.13 & 98.52 & 95.73 & 96.19 \\
4 & 98.06 & 98.14 & 97.18 & 98.09 & 95.83 & 96.82 \\
5 & 98.01 & 98.86 & 97.16 & 98.19 & 95.13 & 97.51 \\
\hline
\end{tabular}


Table 3. 2W-SME of different EVA fiber under 0.27 MPa.

\begin{tabular}{ccccccc}
\hline \multirow{2}{*}{ Cycles } & \multicolumn{2}{c}{ EVA-6M } & \multicolumn{2}{c}{ EVA-8M } & \multicolumn{2}{c}{ EVA-10M } \\
\cline { 2 - 7 } & $\begin{array}{c}\boldsymbol{R}_{\mathbf{a}, \mathbf{2 W}} \\
\mathbf{( \% )}\end{array}$ & $\begin{array}{c}\boldsymbol{R}_{\mathbf{r}, \mathbf{2 W}} \\
\mathbf{( \% )}\end{array}$ & $\begin{array}{c}\boldsymbol{R}_{\mathbf{a}, \mathbf{2 W}} \\
\mathbf{( \% )}\end{array}$ & $\begin{array}{c}\boldsymbol{R}_{\mathbf{r}, \mathbf{2 W}} \\
\mathbf{( \% )}\end{array}$ & $\begin{array}{c}\boldsymbol{R}_{\mathbf{a}, \mathbf{2 W}} \\
\mathbf{( \% )}\end{array}$ & $\begin{array}{c}\boldsymbol{R}_{\mathbf{r}, \mathbf{2 W}} \\
\mathbf{( \% )}\end{array}$ \\
\hline 1 & 10.32 & 84.24 & 13.75 & 86.88 & 12.20 & 93.59 \\
2 & 9.18 & 93.68 & 13.62 & 92.07 & 12.33 & 93.59 \\
3 & 8.94 & 95.53 & 13.50 & 93.56 & 12.26 & 95.27 \\
4 & 8.81 & 96.48 & 13.35 & 96.03 & 12.20 & 96.72 \\
5 & 8.69 & 97.12 & 13.35 & 96.23 & 12.26 & 97.39 \\
\hline
\end{tabular}

\subsection{Effect of Crosslink Density and Applied Stress on Reversible Strain of EVA Fiber}

EVA-8M and EVA-10M were chosen to evaluate the reversible strain of EVA fiber with different crosslink densities. EVA-8M was subjected to different constant stress $(0.22 \mathrm{MPa}, 0.32 \mathrm{MPa}$, and $0.37 \mathrm{MPa}$ ) and the results from five consecutive cycles were illustrated in Figure $7 \mathrm{a}-\mathrm{c}$. The same shape memory experiment profile was applied to EVA-10M (Figure $7 \mathrm{~d}-\mathrm{f}$ ). The relationship between applied stress and reversible strain was illustrated in Figure 8. The $R_{\mathrm{a}, 2 \mathrm{~W}}$ of EVA-8M increased with applied stress increase and reached a maximum value of $13.84 \%$ when the stress increased to $0.32 \mathrm{MPa}$ (see Figure 8). The degree of molecular chain orientation of EVA fiber was increased by increased external stress, which provides an additional template skeleton for the recrystallization of the segments, further increasing the reversible strain during cooling [42,53]. When the stress was further increased to $0.37 \mathrm{MPa}$, the $R_{\mathrm{a}, 2 \mathrm{~W}}$ of EVA-10M increased to $14.19 \%, R_{\mathrm{a}, 2 \mathrm{~W}}$ of EVA-8M reduced to $12.83 \%$. This phenomenon was attributed to the competitive relationship between the crosslinked network and the crystalline phase [58,59]. The crosslinked network memorized the initial shape and provides entropy elasticity for shape recovery. The entropic elastic restoring force of EVA fiber increased with the crosslink density increasing. When the external stress increased continuously, the segmental motion of EVA-8M was limited, and further, its recrystallization ability was limited. Therefore, the reversible strain value of EVA-10M with a large crosslink density is higher than that of EVA-8M.
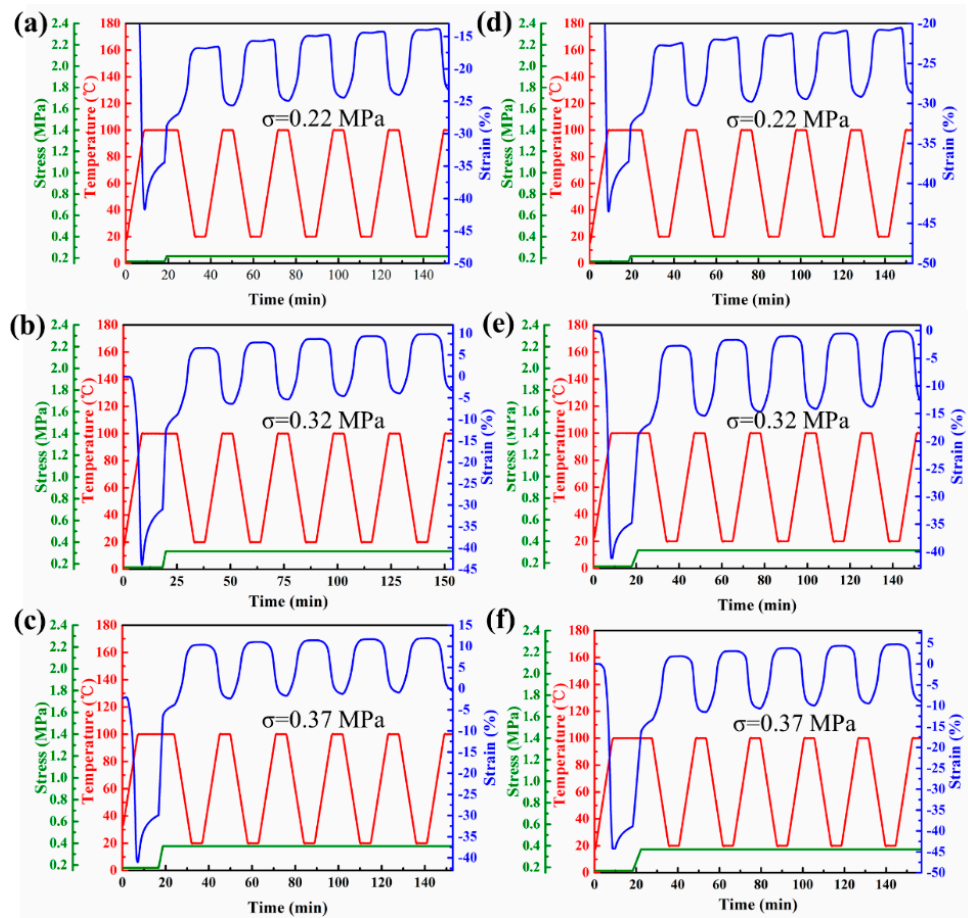

Figure 7. 2W-SME cycles of (a-c) EVA-8M, and (d-f) EVA-10M with increasing constant stress. 


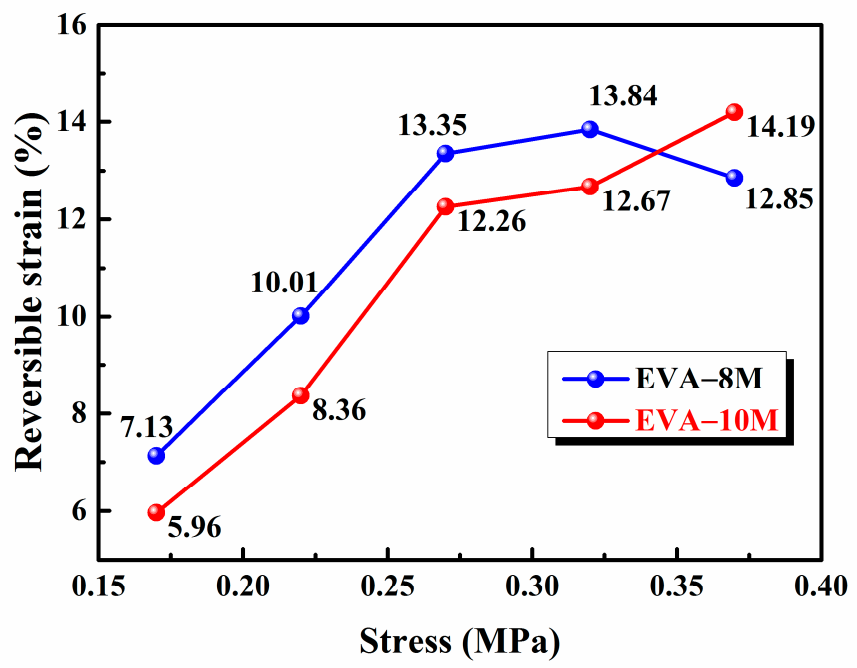

Figure 8. Effect of UV curing time and applied stress on the reversible strain of the crosslinked EVA fibers. (Reversible strain was calculated by the fifth heating-cooling cycle).

\subsection{Macroscopic Thermo-Actuated 2W-SME of EVA Fiber under Constant Stress}

The macroscopic reversible shape memory behavior by using electric heating quartz tube as shown in Figure 9. The length of the heating tube was $15 \mathrm{~cm}$. EVA-10M fiber passed through the quartz heating tube and hung a $2 \mathrm{~g}$ weight. The heating of the quartz tube was achieved using a fixed resistance wire external to the tube. The macroscopic thermo-actuated 2W-SME was observed. The weight increased rapidly (approximately $14 \mathrm{~mm}$ ) within $40 \mathrm{~s}$ during the heating process as illustrated in Figure $9 \mathrm{a}-\mathrm{c}$ and it dropped slowly during the cooling process (see Figure $9 \mathrm{~d}-\mathrm{f}$ ). The single fiber could lift more than 143 times its own weight and had a 9\% reversible actuation strain. One of the important characteristics of fibers is the flexibility in structural design. A $2 \mathrm{~g}$ weight was hung on one end of a folded single fiber, as shown in Figure 10a,b. Upon heating, EVA fiber contracted and lifted the $2 \mathrm{~g}$ weight with a stroke of $29 \mathrm{~mm}$, showed a reversible strain of $19 \%$. A much higher driving force can be applied after winding a single fiber into a coil, as shown in Figure 10c,d. The number of load-bearing fibers in the fiber bundle has increased to 20 and was able to lift an object of $74 \mathrm{~g}$ with a comparable reversible displacement. It indicated that the applicability of this 2W-SME EVA fiber could be readily realized through simple structural design, which was restricted in other bulky $2 \mathrm{~W}-\mathrm{SME}$ systems. The reversible shape memory capability of EVA fiber makes them excellent candidate materials for smart textiles, flexible sensor, and actuator applications.

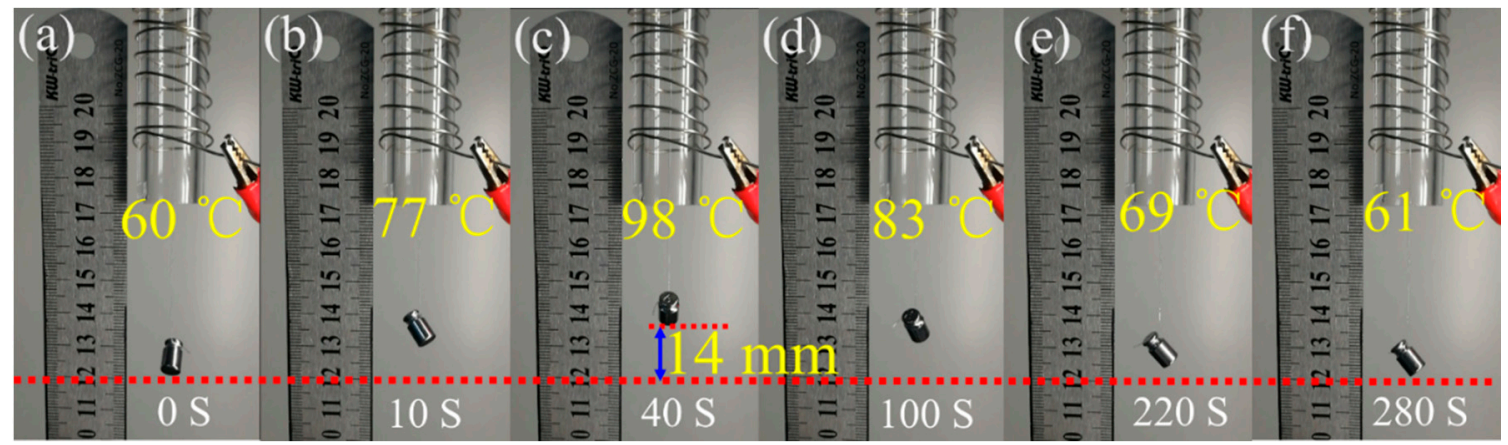

Figure 9. Digital photographs showing the 2W-SME of the EVA-10M fiber under constant stress. 


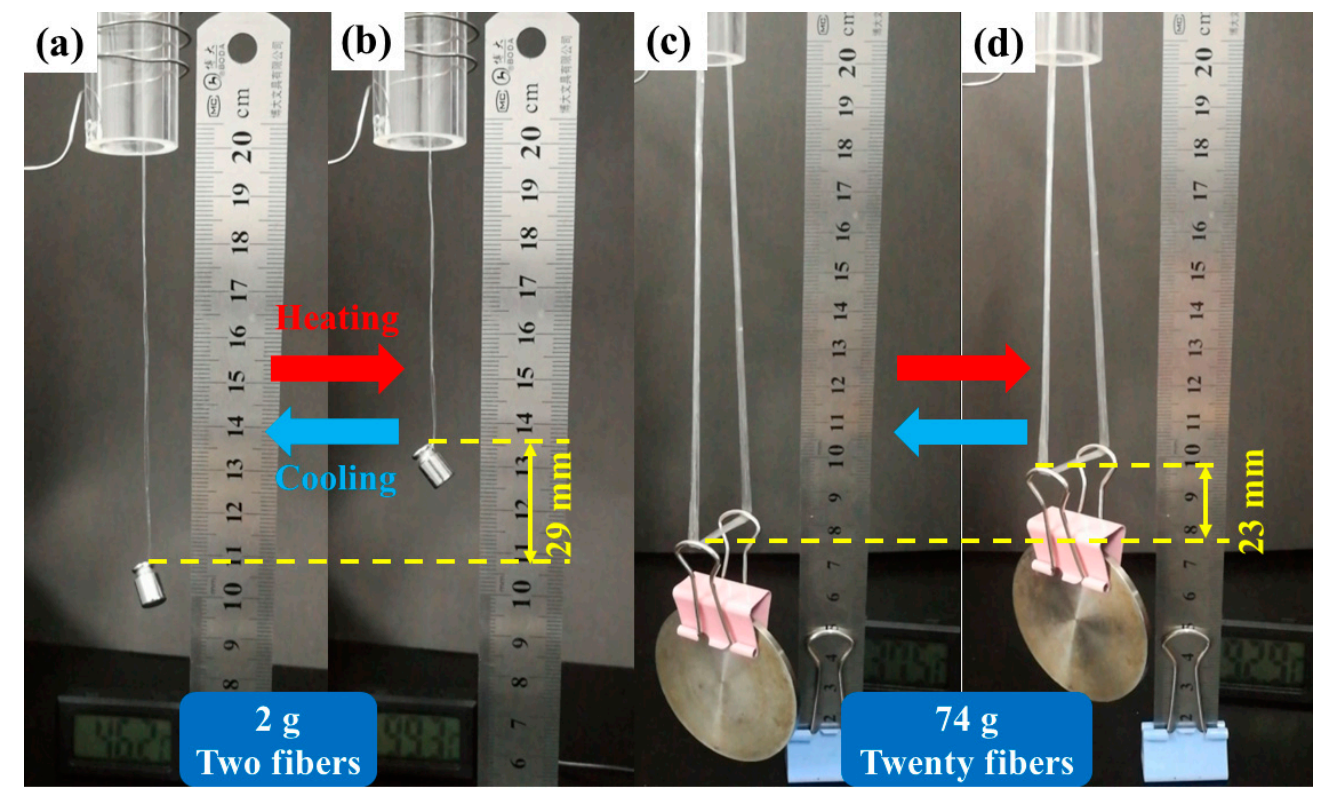

Figure 10. The reversible actuation capability was increased by combing multiple fibers.

\section{Conclusions}

The 2W-SME of EVA fiber was successfully fabricated by melt spinning and UV curing. The properties of two-way shape memory EVA fiber can be easily adjusted by simply varying the UV curing time. TMA thermo-mechanical test revealed that EVA fiber with the suitable crosslink networks exhibited excellent $1 \mathrm{~W}$-SME with $R_{\mathrm{f}, 1 \mathrm{~W}}$ and $R_{\mathrm{r}, 1 \mathrm{~W}}$ of more than $95 \%$. Moreover, the CIE phenomenon appeared in $1 \mathrm{~W}-\mathrm{SME}$ cycle, which was crucial for achieving $2 \mathrm{~W}-\mathrm{SME}$. Systematic evaluation indicated that the crosslink density and applied stress greatly influenced the $2 \mathrm{~W}-\mathrm{SME}$. EVA-10M with higher gel fraction could withstand high loads (stress of $0.37 \mathrm{MPa}$ ) and had a reversible strain of $14.19 \%$. Macroscopic thermo-actuated 2W-SME showed that EVA-10M fiber could lift more than 143 times its own weight and achieve $9 \%$ reversible actuation. The reversible actuation capability was significantly enhanced by a simple winding design of the single EVA fiber. The design of two-way shape memory EVA fiber has the advantages of low equipment requirements, low cost, and convenient operation. It is expected to realize the application of commercial polymers in the fields of smart textiles, flexible actuators, and artificial muscles.

Author Contributions: Conceptualization, methodology, formal analysis, data curation, writing, X.Q.; Formal analysis, data curation, W.Y.; Methodology, investigation, L.Y. and W.W.; Data curation, H.L., Y.W., and S.Z.; Writing-review and editing, Y.Z., X.L., Y.D., and Y.F.; Funding acquisition, supervision Y.Z. and Y.D.; Supervision, project administration, Y.D. and Y.F.

Funding: This work was supported by the Natural Science Foundation of Zhejiang Province (Grant No. LY19E030010), National Natural Science Foundation of China (Grant No. 51703204), and Key Program for International Science and Technology Cooperation Projects of Ministry of Science and Technology of China (Grant No. 2016YFE0125900).

Conflicts of Interest: The authors declare no conflict of interest.

\section{References}

1. Bogue, R. Smart materials: A review of capabilities and applications. Assem. Autom. 2014, 34, 16-22. [CrossRef]

2. Leng, J.; Lan, X.; Liu, Y.; Du, S. Shape-memory polymers and their composites: Stimulus methods and applications. Prog. Mater. Sci. 2011, 56, 1077-1135. [CrossRef]

3. Hu, J.; Zhu, Y.; Huang, H.; Lu, J. Recent advances in shape-memory polymers: Structure, mechanism, functionality, modeling and applications. Prog. Polym. Sci. 2012, 37, 1720-1763. [CrossRef] 
4. Karger-Kocsis, J.; Keki, S. Review of progress in shape memory epoxies and their composites. Polymers 2017, 10, 34. [CrossRef] [PubMed]

5. Liu, Y.; Du, H.; Liu, L.; Leng, J. Shape memory polymers and their composites in aerospace applications: A review. Smart Mater. Struct. 2014, 23, 023001. [CrossRef]

6. Dong, Y.; Xia, H.; Zhu, Y.; Ni, Q.Q.; Fu, Y. Effect of epoxy-graft-polyoxyethylene octyl phenyl ether on preparation, mechanical properties and triple-shape memory effect of carbon nanotube/water-borne epoxy nanocomposites. Compos. Sci. Technol. 2015, 120, 17-25. [CrossRef]

7. Li, X.; Zhu, Y.; Dong, Y.; Liu, M.; Ni, Q.; Fu, Y. Epoxy resin composite bilayers with triple-shape memory effect. J. Nanomater. 2015. [CrossRef]

8. Zhao, Q.; Qi, H.J.; Xie, T. Recent progress in shape memory polymer: New behavior, enabling materials, and mechanistic understanding. Prog. Polym. Sci. 2015, 49, 79-120. [CrossRef]

9. Gao, J.; Chen, W.; Yu, B.; Fan, P.; Zhao, B.; Hu, J.; Zhang, D.; Fang, G.; Peng, F. Effect of temperature on the mechanical behaviours of a single-ply weave-reinforced shape memory polymer composite. Compos. Part $B$ 2019, 159, 336-345. [CrossRef]

10. Pan, Z.; Huang, R.; Liu, Z. Prediction of the thermomechanical behavior of particle reinforced shape memory polymers. Polym. Compos. 2019, 40,353-363. [CrossRef]

11. Wang, E.; Dong, Y.; Islam, M.Z.; Yu, L.; Liu, F.; Chen, S.; Qi, X.; Zhu, Y.; Fu, Y.; Xu, Z. Effect of graphene oxide-carbon nanotube hybrid filler on the mechanical property and thermal response speed of shape memory epoxy composites. Compos. Sci. Technol. 2019, 169, 209-216. [CrossRef]

12. Liu, R.; Kuang, X.; Deng, J.; Wang, Y.C.; Wang, A.C.; Ding, W.; Lai, Y.C.; Chen, J.; Wang, P.; Lin, Z. Shape memory polymers for body motion energy harvesting and self-powered mechanosensing. Adv. Mater. 2018, 30, 1705195. [CrossRef] [PubMed]

13. Li, S.; Wang, T.X.; Chen, H.M.; Salvekar, A.V.; Naveen, B.S.; Xu, Q.; Weng, Y.; Guo, X.; Chen, Y.; Huang, W.M. A Brief Review of the Shape Memory Phenomena in Polymers and Their Typical Sensor Applications. Polymers 2019, 11, 1049.

14. Besse, N.; Rosset, S.; Zarate, J.J.; Shea, H. Flexible active skin: Large reconfigurable arrays of individually addressed shape memory polymer actuators. Adv. Mater. Technol. 2017, 2, 1700102. [CrossRef]

15. Ge, F.; Lu, X.; Xiang, J.; Tong, X.; Zhao, Y. An optical actuator based on gold-nanoparticle-containing temperature-memory semicrystalline polymers. Angew. Chem. Int. Ed. 2017, 56, 6126-6130. [CrossRef] [PubMed]

16. Hu, J.; Chen, S. A review of actively moving polymers in textile applications. J. Mater. Chem. 2010, 20, 3346-3355. [CrossRef]

17. Castano, L.M.; Flatau, A.B. Smart fabric sensors and e-textile technologies: A review. Smart Mater. Struct. 2014, 23, 053001. [CrossRef]

18. Lee, J.H.; Hinchet, R.; Kim, S.K.; Kim, S.H.; Kim, S.W. Shape memory polymer-based self-healing triboelectric nanogenerator. Energy Environ. Sci. 2015, 8, 3605-3613. [CrossRef]

19. Luo, X.; Mather, P.T. Shape memory assisted self-healing coating. ACS Macro Lett. 2013, 2, 152-156. [CrossRef]

20. Mirvakili, S.M.; Hunter, I.W. Artificial muscles: Mechanisms, applications, and challenges. Adv. Mater. 2018, 30, 1704407. [CrossRef]

21. Yip, M.C.; Niemeyer, G. On the control and properties of supercoiled polymer artificial muscles. IEEE Trans. Robot. 2017, 33, 689-699. [CrossRef]

22. Wang, J.; Sun, L.; Zou, M.; Gao, W.; Liu, C.; Shang, L.; Gu, Z.; Zhao, Y. Bioinspired shape-memory graphene film with tunable wettability. Sci. Adv. 2017, 3, e1700004. [CrossRef] [PubMed]

23. Li, C.; Qiu, L.; Zhang, B.; Li, D.; Liu, C.Y. Robust Vacuum-/Air-Dried Graphene Aerogels and Fast Recoverable Shape-Memory Hybrid Foams. Adv. Mater. 2016, 28, 1510-1516. [CrossRef] [PubMed]

24. Santo, L. Shape memory polymer foams. Prog. Aerosp. Sci. 2016, 81, 60-65. [CrossRef]

25. van Meerbeek, I.M.; Murray, B.C.M.; Kim, J.W.; Robinson, S.S.; Zou, P.X.; Silberstein, M.N.; Shepherd, R.F. Morphing Metal and Elastomer Bicontinuous Foams for Reversible Stiffness, Shape Memory, and Self-Healing Soft Machines. Adv. Mater. 2016, 28, 2801-2806. [CrossRef] [PubMed]

26. Zhang, F.; Zhang, Z.; Zhou, T.; Liu, Y.; Leng, J. Shape memory polymer nanofibers and their composites: Electrospinning, structure, performance, and applications. Front. Mater. 2015, 2, 1-10. [CrossRef]

27. Aslan, S.; Kaplan, S. Thermomechanical and shape memory performances of thermo-sensitive polyurethane fibers. Fibers Polym. 2018, 19, 272-280. [CrossRef] 
28. Hu, J.; Lu, J. Shape memory fibers. In Handbook of Smart Textiles; Tao, X., Ed.; Springer: Singapore, 2015; pp. 183-207.

29. Li, G.; Zhang, P. A self-healing particulate composite reinforced with strain hardened short shape memory polymer fibers. Polymer 2013, 54, 5075-5086. [CrossRef]

30. Zhang, P.; Li, G. Structural relaxation behavior of strain hardened shape memory polymer fibers for self-healing applications. J. Polym. Sci. Part B 2013, 51, 966-977. [CrossRef]

31. Gök, M.O.; Bilir, M.Z.; Gürcüm, B.H. Shape-memory applications in textile design. Procedia Soc. Behav. Sci. 2015, 195, 2160-2169. [CrossRef]

32. Hu, J.; Meng, H.; Li, G.; Ibekwe, S.I. A review of stimuli-responsive polymers for smart textile applications. Smart Mater. Struct. 2012, 21, 053001. [CrossRef]

33. Yang, Q.; Li, G. Investigation into stress recovery behavior of shape memory polyurethane fiber. J. Polym. Sci. Part B 2014, 52, 1429-1440. [CrossRef]

34. Chung, T.; Romo-Uribe, A.; Mather, P.T. Two-way reversible shape memory in a semicrystalline network. Macromolecules 2008, 41, 184-192. [CrossRef]

35. Burke, K.A.; Mather, P.T. Soft shape memory in main-chain liquid crystalline elastomers. J. Mater. Chem. 2010, 20, 3449-3457. [CrossRef]

36. Li, J.; Rodgers, W.R.; Xie, T. Semi-crystalline two-way shape memory elastomer. Polymer 2011, 52, 5320-5325. [CrossRef]

37. Haines, C.S.; Lima, M.D.; Li, N.; Spinks, G.M.; Foroughi, J.; Madden, J.D.; Kim, S.H.; Fang, S.; de Andrade, M.J.; Göktepe, F. Artificial muscles from fishing line and sewing thread. Science 2014, 343, 868-872. [CrossRef]

38. Kanik, M.; Orguc, S.; Varnavides, G.; Kim, J.; Benavides, T.; Gonzalez, D.; Anikeeva, P. Strain-programmable fiber-based artificial muscle. Science 2019, 365, 145-150.

39. Zhao, J.; Chen, M.; Wang, X.; Zhao, X.; Wang, Z.; Dang, Z.M.; Ma, L.; Hu, G.H.; Chen, F. Triple shape memory effects of cross-linked polyethylene/polypropylene blends with cocontinuous architecture. ACS Appl. Mater. Interfaces 2013, 5, 5550-5556. [CrossRef]

40. Dolynchuk, O.; Kolesov, I.; Androsch, R.; Radusch, H.J. Kinetics and dynamics of two-way shape-memory behavior of crosslinked linear high-density and short-chain branched polyethylenes with regard to crystal orientation. Polymer 2015, 79, 146-158. [CrossRef]

41. Navarro-Baena, I.; Sessini, V.; Dominici, F.; Torre, L.; Kenny, J.M.; Peponi, L. Design of biodegradable blends based on PLA and PCL: From morphological, thermal and mechanical studies to shape memory behavior. Polym. Degrad. Stab. 2016, 132, 97-108. [CrossRef]

42. Qian, C.; Dong, Y.; Zhu, Y.; Fu, Y. Two-way shape memory behavior of semi-crystalline elastomer under stress-free condition. Smart Mater. Struct. 2016, 25, 085023. [CrossRef]

43. Wang, K.; Jia, Y.G.; Zhu, X. Two-way reversible shape memory polymers made of cross-linked cocrystallizable random copolymers with tunable actuation temperatures. Macromolecules 2017, 50, 8570-8579. [CrossRef]

44. Xie, H.; Li, L.; Deng, X.Y.; Cheng, C.Y.; Yang, K.K.; Wang, Y.Z. Reinforcement of shape-memory poly (ethylene-co-vinyl acetate) by carbon fibre to access robust recovery capability under resistant condition. Compos. Sci. Technol. 2018, 157, 202-208. [CrossRef]

45. Qian, C.; Zhu, Y.; Dong, Y.; Fu, Y. Vapor-grown carbon nanofiber/poly (ethylene-co-vinyl acetate) composites with electrical-active two-way shape memory behavior. J. Intell. Mater. Syst. Struct. 2017, 28, 2749-2756. [CrossRef]

46. Yao, Y.; Wei, H.; Wang, J.; Lu, H.; Leng, J.; Hui, D. Fabrication of hybrid membrane of electrospun polycaprolactone and polyethylene oxide with shape memory property. Compos. Part B 2015, 83, $264-269$. [CrossRef]

47. Budun, S.; İşgören, E.; Erdem, R.; Yüksek, M. Morphological and mechanical analysis of electrospun shape memory polymer fibers. Appl. Surf. Sci. 2016, 380, 294-300. [CrossRef]

48. Iregui, A.; Irusta, L.; Llorente, O.; Martin, L.T.; Calvo-Correas, A.; Eceiza, A. Gonzalez, Electrospinning of cationically polymerized epoxy/polycaprolactone blends to obtain shape memory fibers (SMF). Eur. Polym. J. 2017, 94, 376-383. [CrossRef]

49. Yao, Y.; Luo, Y.; Lu, B.; Wang, B. Remotely actuated porous composite membrane with shape memory property. Composite Struct. 2018, 192, 507-515. [CrossRef] 
50. Ma, L.; Zhao, J.; Wang, X.; Chen, M.; Liang, Y.; Wang, Z.; Yu, Z.; Hedden, R.C. Effects of carbon black nanoparticles on two-way reversible shape memory in crosslinked polyethylene. Polymer 2015, 56, 490-497. [CrossRef]

51. Amintowlieh, Y.; Tzoganakis, C.; Penlidis, A. The effect of depth and duration of UV radiation on polypropylene modification via photoinitiation. J. Appl. Polym. Sci. 2014, 131, 21. [CrossRef]

52. Zhang, H.; Shang, Y.; Li, M.; Zhao, H.; Wang, X.; Han, B. Theoretical study on the reaction mechanism in the UV radiation cross-linking process of polyethylene. RSC Adv. 2016, 6, 110831-110839. [CrossRef]

53. Xu, H.; Zhang, Y.; Yang, J.; Ye, L.; Wu, Q.; Qu, B.; Wang, Q.; Wang, Z. Simultaneous enhancements of toughness and tensile strength for thermoplastic/elastomer blends through interfacial photocrosslinking with UV radiation. Polym. Chem. 2013, 4, 3028-3038. [CrossRef]

54. Jin, J.; Chen, S.; Zhang, J. UV aging behaviour of ethylene-vinyl acetate copolymers (EVA) with different vinyl acetate contents. Polym. Degrad. Stab. 2010, 95, 725-732. [CrossRef]

55. Han, J.L.; Lai, S.M.; Chiu, Y.T. Two-way multi-shape memory properties of peroxide crosslinked ethylene viny-acetate copolymer (EVA)/polycaprolactone (PCL) blends. Polym. Adv. Technol. 2018, 29, 2010-2024. [CrossRef]

56. Xie, H.; Cheng, C.Y.; Deng, X.Y.; Fan, C.J.; Du, L.; Yang, K.K.; Wang, Y.Z. Creating poly (tetramethylene oxide) glycol-based networks with tunable two-way shape memory effects via temperature-switched netpoints. Macromolecules 2017, 50, 5155-5164. [CrossRef]

57. Li, Q.; Zhou, J.; Vatankhah-Varnoosfaderani, M.; Nykypanchuk, D.; Gang, O.; Sheiko, S.S. Advancing reversible shape memory by tuning the polymer network architecture. Macromolecules 2016, 49, 1383-1391. [CrossRef]

58. Dolynchuk, O.; Kolesov, I.; Jehnichen, D.; Reuter, U.; Radusch, H.J.; Sommer, J.U. Reversible shape-memory effect in cross-linked linear poly ( $\varepsilon$-caprolactone) under stress and stress-free conditions. Macromolecules 2017, 50, 3841-3854. [CrossRef]

59. Gao, Y.; Liu, W.; Zhu, S. Polyolefin thermoplastics for multiple shape and reversible shape memory. ACS Appl. Mater. Interfaces 2017, 9, 4882-4889. [CrossRef]

(C) 2019 by the authors. Licensee MDPI, Basel, Switzerland. This article is an open access article distributed under the terms and conditions of the Creative Commons Attribution (CC BY) license (http://creativecommons.org/licenses/by/4.0/). 